\title{
A PROPÓSITO DE LA NUEVA ORIENTACIÓN DADA A LAS PENSIONES DE ARQUITECTURA EN EL EXTRANJERO A MEDIADOS DEL SIGLO XIX. FRANCISCO DE CUBAS Y SU PROYECTO PARA UNA CASA DE MATERNIDAD
}

\author{
José Manuel Prieto González \\ Becario predoctoral en el departamento de $\mathrm{H}^{a}{ }^{a}$ de la Ciencia del C.E.H. del C.S.I.C. Madrid (España)
}

\section{RESUMEN}

Entre las reformas experimentadas en el ámbito de la arquitectura a mediados del siglo pasado se encuentra la subrogación del tradicional y exclusivo enfoque artístico de sus pensiones en el extranjero, por otro que, más en consonancia con los requerimientos del nuevo régimen liberalburgués, concilia los dos componentes básicos de la carrera y la profesión, el arte y la ciencia. Un proyecto del pensionado Francisco de Cubas ejemplifica por vez primera este cambio.

\section{SUMMARY}

One of the reforms that the architectural profession underwent in the mid-nineteenth century was the substitution of the traditional and exclusivelly artistic focus of students sojourns abroad for a tendency that combined the two dominant aspects of architecture: art and science. This transformation was encouraged by the aspiration of the new liberal bourgeois regime. The project of Francisco de Cubas abroad illustrates this development fo the first time.

Siguiendo el ejemplo de su homónima francesa, la Real Academia de Bellas Artes de San Fernando promovió desde bien temprano - 1745-1 la concesión de pensiones en Roma entre sus discípulos de arquitectura, escultura y pintura. A la capital italiana se sumará París como nuevo punto de destino desde fines del XVIII —era el más importante enclave del moderno gusto neoclásico- y los alumnos de grabado optarán también a ellas tiempo después. Dado que Felipe V había derogado en 1718

1 Alicia Quintana señala que el intento tenía precedentes en los reinados de Felipe IV y Carlos II. QUinTANA, A. (1983), La arquitectura y los arquitectos en la Real Academia de Bellas Artes de San Fernando (1744-1774), Xarait ed., Madrid, p. 93. 
una orden anterior que prohibía a sus súbditos ampliar conocimientos en el extranjero $^{2}$, nada impedía ya llevar a la práctica esta iniciativa.

En un primer momento la provisión de las escasas plazas disponibles no se ajustó precisamente a lo que hoy entendemos, en rigor, por una oposición, quedando sujeta muchas veces al capricho o la arbitrariedad del poder real. Algo así fue lo que ocurrió con los dos primeros pensionados que tuvo la arquitectura, Miguel Fernández y José de Hermosilla ${ }^{3}$. Pero las cosas cambiaron cuando los estatutos de la Academia de 1757 incluyeron una primera regulación sobre la materia, bastante escueta por cierto - se limitaba a un solo artículo, el veinte-, que luego se completó con un remedo de reglamento de veintidós puntos. De acuerdo con esta incipiente organización obtuvieron su pensión aquel mismo año Juán de Villanueva y Domingo Antonio Lois y Monteagudo. Durante las décadas siguientes disfrutaron de esa condición privilegiada titulados y no titulados, individuos brillantes en cualquier caso - aunque algunos tuviesen después escasa repercusión en el ámbito profesional-, entre los que se encontraban Isidro González Velázquez (1791), Silvestre Pérez (1791, extraordinaria), Evaristo del Castillo (1791, extraordinaria), Juan Gómez (1804), Fermín Díaz (1817) o Martín López Aguado (1817)4. A su regreso casi todos ellos fueron nombrados académicos de mérito en atención a la aplicación que habían demostrado como pensionados. Asímismo, es muy probable que en más de una ocasión se ligase la concesión de estas pensiones a la obtención del máximo galardón en los concursos generales de arquitectura, concretamente en su modalidad de Primera Clase, que eran organizados con cierta periodicidad por la Academia ${ }^{5}$. Eso es lo que parece haber sucedido en el caso de Aníbal Álvarez, cuya marcha a Roma como pensionado en 1832 coincide con la consecución de un primer premio en la última convocatoria de estos concursos, celebrada en septiembre de 18316; de ese modo, el asunto desarrollado para el concurso, consistente en "proyectar una magnífica biblioteca", habría hecho las veces de ejercicio de oposición a la pensión de Roma. Téngase en cuenta que una pensión ordinaria como era la suya sólo podía ser adjudicada mediante oposición, y no nos consta que hubiese tenido lugar por aquellas fe-

2 Dicha orden había partido de Felipe II en 1559. PUERTO, F. J. (1988), La ilusión quebrada. Botánica, sanidad y política científica en la España ilustrada, Serbal/CSIC ed., Barcelona, p. 9-10.

3 Esas dos primeras plazas fueron legalmente ganadas por Diego de Villanueva y Alejandro González Velázquez; curiosamente, ninguno de ellos llegó a ir a Roma. QUINTANA (1983), p. 93-94.

4 A diferencia de lo que sucederá más adelante, por aquel entonces aun no se exigía a los aspirantes a la pensión mantenerse en estado estudiantil, esto es, sin haber obtenido la titulación. Así, por ejemplo, Fermín Díaz era maestro arquitecto desde 1807 y ello no le impidió ganar la pensión de Roma en 1817 (el 2 de marzo concretamente). Cfr. RODRÍGUEZ, D. y otros (1992), Hacia una nueva idea de la arquitectura. Premios generales de arquitectura de la Real Academia de Bellas Artes de San Fernando (1753 1831), Madrid, p. 191 y ss.

5 Para un conocimiento en profundidad de esos concursos véase RoDRíGUEZ, D. y otros (1992).

6 Cfr. Anónimos (1832), "Bellas Artes" y "Revista Semanal”, Cartas Españolas, 46, 8 -10 y 17-20. 
chas ninguna con este cometido específico. Las pensiones extraordinarias, en cambio, eran una "gracia particular" de la Academia y como tal no implicaban selección de aspirantes, aunque sí debían mediar ciertos méritos por parte del candidato. Precisamente el mismo año que Aníbal Álvarez obtuvo la suya, la Academia concedía otra, pero extraordinaria, a Antonio de Zabaleta. Acababa de regresar éste de París, donde había permanecido por espacio de tres años dedicado al estudio de la arquitectura, y deseaba continuar esos estudios en el extranjero pero "con mayor alivio de su padre", dado que la estancia parisina había sido costeada íntegramente por su familia. De ahí que, previa petición, la Academia de San Fernando le conceda, por R.O. de 6 de abril de 1832, la pensión extraordinaria para pasar a Roma ${ }^{7}$.

Aníbal Álvarez y Antonio de Zabaleta fueron dos de los principales artífices de la reforma del plan de estudios de las Bellas Artes que data de 1844; no en vano uno y otro eran ya por aquellas fechas académicos de mérito de San Fernando. Dicha reforma quedará englobada en la más amplia reestructuración general de toda la enseñanza, promovida por los moderados y aprobada al año siguiente ${ }^{8}$. Consecuencia directa de la misma fue la creación de la Escuela especial de Arquitectura de Madrid que, careciendo aun de autonomía propia durante algunos años, si bien es cierto que mas de iure que de facto en muchos aspectos, pasó a formar parte de la llamada Escuela de Nobles Artes de la Real Academia de San Fernando. A raíz de todo esto la enseñanza de la arquitectura recibió un gran impulso que hizo posible eludir el trasnochado sistema pedagógico que había funcionado hasta entonces en aquella corporación ${ }^{9}$. Sin embargo, la segregación paulatina que fue experimentando la Escuela especial de Arquitectura con respecto a la Academia no llevó aparejado un desplazamiento correlativo en lo referente a capacidad decisoria en el tema de las pensio-

\footnotetext{
7 Archivo de la Real Academia de Bellas Artes de San Fernando, legajo 49-7/1. Para cualquier otra información sobre Zabaleta véase la monografía de SAZATORNIL, L. (1992), Antonio de Zabaleta (18031864). La renovación romántica de la arquitectura española, Tantín ed., Santander.

8 En efecto, la reforma específica de la enseñanza de las bellas artes, aprobada por R.D. de 25 de septiembre de 1844 , es anterior en un año a la general, que data del 17 de septiembre de 1845 , la cual incluía también a las bellas artes. Una y otra fueron impulsadas por Pedro José Pidal, a la sazón ministro de la Gobernación, además de individuo de la sección de arquitectura de la Academia de San Fernando, como ya ha señalado el profesor Pedro Navascués. Cfr. Ministerio de la Gobernación (1844), "Aprobando el plan de enseñanza para los estudios de las bellas artes de la Real Academia de San Fernando", Colección de las leyes, decretos y declaraciones de las Cortes, y de los reales decretos, órdenes, resoluciones y reglamentos generales expedidos por los respectivos ministerios, XXXII, 232-233; véase también NAVASCUÉs, P. (1994), "La Escuela de Arquitectura de Madrid (1844-1914)", Escuela Técnica Superior de Arquitectura de Madrid. Memoria 1991-1993, 10-17. Para el plan general cfr. M. de la Gobernación (1845), XXXV, 197-246, y PESET, M. y J.L. (1974), La Universidad Española (siglos XVIII y XIX). Despotismo ilustrado y revolución liberal, Taurus ed., Madrid, p. 429 y ss.

9 Cfr. NAVASCUÉs, P. (1973), Arquitectura y arquitectos madrileños del siglo XIX, Madrid, p. 2425 y $95-97$.
} 
nes. En efecto, este capítulo siguió siendo prerrogativa exclusiva de la institución matriz a través de sus respectivas secciones.

Los primeros pensionados por la arquitectura de la nueva etapa fueron Gerónimo $^{10}$ de la Gándara y Francisco Jareño. Hasta 1847 la Academia no consideró oportuno crear ninguna plaza puesto que la reforma del plan de estudios estaba tan próxima que no habría tenido tiempo de dar sus frutos; es decir, aun no habría podido formar aspirantes lo suficientemente capaces como para optar a una pensión de ese tipo. Por R.O. de 15 de septiembre de ese año se creaban dos pensiones de doce mil reales cada una para los alumnos de Arquitectura, que debían proveerse, en principio, en los dos años siguientes. Sin embargo, las cosas no salieron como se esperaba. El tribunal encargado de calificar los ejercicios de oposición de la de 1848, aunque designó un ganador por votación secreta —-De la Gándara-, estimó que los dos candidatos presentados habían demostrado méritos suficientes para hacerse acreedores de la beca. En consecuencia, sus miembros acordaron pedir al gobierno, con carácter extraordinario, otra pensión para el segundo opositor - Francisco JareñoNada displicente con el requerimiento de los académicos, la autoridad competente accede a esta petición pero, a cambio, suprime la plaza que tendría que haber sido cubierta al año siguiente ${ }^{11}$. Pues bien, que la Academia era en el fondo, si no en la forma, una institución reacia al proceso reformista que estaba teniendo lugar en su derredor por aquel entonces, es algo que se deduce claramente al comprobar la falta de correspondencia que existe entre la evolución seguida por los tradicionales cometidos que ahora se desglosan de ella en mayor o menor medida - docencia - y los que permanecen por completo bajo su directa responsabilidad - pensiones-. Al socaire de la renovación impulsada desde el gobierno, la enseñanza de la arquitectura estaba registrando una considerable mejora, alentada, entre otras cosas, por la más completa sistematización de las materias de estudio, por el equilibrio logrado entre los conocimientos artísticos y los científicos, y por la definición de unos mínimos relacionados con la función docente. El sistema de pensiones, en cambio, no había conocido variación alguna a pesar de albergar serias deficiencias en su organigrama. En este sentido, escasa o nula, por excesivamente genérica, habría sido la aportación del Reglamento que ha de observarse con los pensionados en cortes extrangeras para el estudio de las nobles artes, aprobado por el Rey nuestro Señor en 9 de marzo de $1830^{12}$. Así pues, a la espera de un verdadero reglamento que permitiera sol-

10 Hemos optado por mantener la grafía original; de ahí el escribir "Gerónimo" con "G" y no con "J".

11 Archivo de la Real Academia de Bellas Artes de San Fernando, legajo 49-7/1.

12 Puede consultarse en la Biblioteca de la Academia de San Fernando a través de la signatura F4776. Contiene únicamente cuestiones de carácter secundario para lo que aquí estamos tratando; aun así, cabe destacar la exigencia formulada a los aspirantes en relación a que deben acreditar su "conducta moral y política" - artículo $3^{\circ}$ - y la definición del objetivo ulterior de estas salidas al extranjero: "perfeccionarse" - artículo $7^{\circ}$ - No obstante lo dicho, menos provecho sacamos si cabe del Reglamento 
ventar tales fallos, esta convocatoria de 1848 apenas difería de todas las anteriores desde el punto de vista de los objetivos previstos: los intereses artísticos de la Academia se hacían omnipresentes. La única novedad digna de mención, registrada en el terreno de la metodología de las oposiciones, consistía en la subrogación de la vieja fórmula basada en el binomio pensado-repente por un nuevo sistema que primaba en exclusiva la ejecución rápida —no más de quince horas- e incomunicada de los diferentes ejercicios.

A las pensiones podían optar aquellos estudiantes que, habiendo superado satisfactoriamente el último año de la carrera, aun no hubieran recibido el título de arquitecto; en caso de concesión, éste se entregaría a la vuelta ${ }^{13}$. Es decir, los destinatarios naturales de las pensiones estaban a medio camino entre la etapa de formación y el mundo profesional. La salida transitoria intermedia que les brindaba la Academia con estas becas tendía así a retardar el acceso a la profesión, dilatando por contra el período formativo. En efecto, la finalidad primordial de las pensiones se cifraba en el perfeccionamiento y la ampliación de los conocimientos que los beneficiarios habían adquirido durante los años de carrera ${ }^{14}$. Desde esta perspectiva, dicho objetivo debería alcanzar por igual a las dos partes, científica y artística, en que aquélla se fundamentaba. Sin embargo, hasta ese momento la Academia había hecho valer su autoridad y sus intereses como institución para orientar básicamente hacia la faceta artística tanto los ejercicios de oposición como los envíos periódicos de los pensionados: en ellos lo importante era el dibujo y el lavado empleados en la copia de fragmentos o edificios completos de entre los más emblemáticos del pasado; apenas se promueve la elaboración de proyectos originales; a lo sumo podía pedirse la restauración de algún monumento deteriorado o en ruinas como ejercicio erudito de reconstrucción arqueológica. Buena parte del interés estaba centrado en el acopio positivista de datos curiosos e inéditos, lo cual conducía a realizar reiterativas mediciones de los monumentos, nunca satisfechas del todo, cálculos de proporciones, etc. De este modo, el equilibrio arte-ciencia conseguido en los estudios de carrera gracias a la refor-

\footnotetext{
interior y doméstico para los pensionados españoles en Roma, propuesto por la Real Academia de nobles artes de San Fernando, y aprobado por el Rey nuestro Señor en 19 de enero de 1832; se encuentra en la misma biblioteca bajo la signatura F-3519.

13 Por R.O. de 17 de mayo de 1848 se aprobó el Reglamento de los ejercicios que deben practicar los alumnos de la Escuela de Arquitectura para obtener el título de Arquitectos, en virtud del cual quedaban exentos de los mismos "los alumnos que hayan obtenido por oposición pensiones en el extranjero y remitido sin interrupción los envíos". Ello les permitía, asímismo, escapar a los dos años de prácticas que se habían previsto en el referido reglamento para nada más acabar la carrera; sin embargo, "no podrán [los pensionados] solicitar el título hasta transcurridos dos años que se consideran conmutados con los de práctica". Archivo de la Real Academia de Bellas Artes de San Fernando, legajo 32-4/1. Como es lógico, los pensionados no volverían a España al cabo de esos dos años a tramitar la solicitud de sus títulos, sino que dejarían ésta en suspenso hasta su vuelta definitiva.

14 Así lo anticipaba ya el artículo $7^{\circ}$ del Reglamento que ha de observarse..., de 1830.
} 
ma, no tenía su equivalente en este otro ámbito. Sorprende, en tal sentido, que los encargados de organizar la convocatoria de pensiones de 1848, Antonio de Zabaleta y Aníbal Álvarez ${ }^{15}$, quienes compartían a un tiempo la triple condición de expensionados, profesores de la Escuela especial y académicos, hayan dejado a un lado los fundados argumentos que esgrimieron en su día cuando, como portavoces de un mayoritario estado de opinión que ellos mismos capitanearon, reclamaban insistentemente la reforma de un plan de estudios que precisaba urgente atención en su parte científica ${ }^{16}$. Y es que, al redactar las bases de las oposiciones, dicen pretender que los aspirantes prueben, no tanto una "aptitud" general, que daban por supuesta en el hecho mismo de haber aprobado todos los años de la carrera, cuanto en "juzgar el mérito relativo de los concurrentes y descubrir cuál es el más sobresaliente en la parte artística, que es la que han de perfeccionar estudiando los grandes monu-

15 Fueron nombrados para tal fin por la Sección de arquitectura de la Academia, a la que pertenecían, el 11 de abril de 1848. Archivo de la Real Academia de Bellas Artes de San Fernando, legajo 49-7/1.

16 No es que defendieran con ello una hipertrofia de los conocimientos científicos sobre los artísticos en la carrera; clamaban, más que nada, por la justa equiparación entre ambos pero no tanto por cubrir una determinada cuota - 50/50 - fijada a priori, cuanto por responder así a lo que eran exigencias reales planteadas en el día a día de la profesión. Eso sí, todo ello sin renunciar, por supuesto, al distintivo artístico que les caracterizaba.

Resulta significativa la misiva que los profesores de la Escuela especial de Arquitectura dirigen a la Reina, y por extensión al gobierno, en julio de 1845. Los firmantes, entre quienes se encontraban Álvarez y Zabaleta, se quejan de que durante los diez meses que habían transcurrido desde la aprobación del R.D. de 25 de septiembre de 1844, la Academia no había hecho nada por su "desarrollo y aplicación"; creen que "se pierde tiempo interpretando equivocadamente los decretos de V.M. en todo lo que tiende a corregir los abusos hoy existentes en la profesión". Su objetivo no era otro que "dar a la enseñanza la unidad que requiere". Archivo de la Real Academia de Bellas Artes de San Fernando, legajo 32-3/1 (Documento fechado el 10 de julio de 1845). Pues bien, todo indica que entre las motivaciones que había suscitado esta dura crítica a la Academia figuraba la poca atención prestada hasta ese momento al reforzamiento de la parte científica de la carrera. En este sentido, la llamada de atención de los profesores parece haber surtido efecto puesto que, un año más tarde, Zabaleta afirmaba que esa parte "se halla enteramente satisfecha, siendo fundamental y absoluto el cambio operado en esta carrera, que por lo tanto ha tomado una importancia social de que antes carecía. [...]. En esta parte, lo repetimos, nada se ha dejado por hacer; la educación del arquitecto será completa". Por contra, expresaba cierto temor por el hecho de que la parte artística quedaba "algún tanto postergada". ZABALETA, A. y AMADOR, J. (1846), "Observaciones sobre el decreto de organización de la Escuela especial de Arquitectura", Boletín Español de Arquitectura, I, 62-64; p. 62.

Hubo algún otro profesor como José Jesús de Lallave cuya inicial formación ingenieril le llevó a batallar casi exclusivamente en favor de los estudios científicos de la carrera. La tarea de Zabaleta y Álvarez fue mucho más comprometida con la reforma a nivel general; por lo demás, tal vez fue su capacidad de liderazgo lo que les llevó con relativa prontitud a la dirección de la Escuela: entre 1854-55 el primero $y$ entre 1857-64 el segundo. 
mentos de las épocas pasadas" 17 . Al margen del trámite específico de la oposición, visto así, semejante planteamiento suponía incluso una involución con respecto a otros anteriores ${ }^{18}$. Así pues, la única explicación que le encontramos a esta aparente contradicción es que, quienes así se pronunciaban, no lo hacían en su condición de profesores de la Escuela especial de Arquitectura, sino en calidad de académicos de San Fernando. Esta circunstancia pone de manifiesto el empleo de registros ideológicos distintos en función del foro o del contexto en que se viertan esos pronunciamientos. Ahora bien, más que de contradicciones de pensamiento habría que hablar de acomodos del mismo a los distintos enfoques que sobre el particular se tenían en uno y otro ámbito. La Academia, que era la que sacaba a oposición las pensiones, era una institución artística que, como tal, pretendía salvaguardar y priorizar a toda costa la imagen artística de la arquitectura, en detrimento de aquella otra apuntalada por el gobierno mediante la reforma, como era su deber, la cual, enfatizando sus componentes científico-técnicos, la acercaba a los dominios de la ingeniería. Se buscaba así, precisamente, marcar distancias con los ingenieros, que, no pudiendo o no queriendo ser artistas, se quedaban en meros constructores. De ahí que la Academia no viera con buenos ojos la inminente puesta en marcha de una Escuela preparatoria para las especiales de Caminos, Canales y Puertos, de Minas y Arquitectura ${ }^{19}$; del mismo modo que tampoco dio en su día - 1841 - el plácet al plan de estudios propuesto por José Jesús de Lallave ${ }^{20}$ por la misma razón, esto es, que en ambas iniciativas se sobredimensionaban las materias científicas. Por contra, quienes respaldaban estas propuestas aducían razones de competitividad con los ingenieros, que venían

17 Archivo de la Real Academia de Bellas Artes de San Fernando, legajo 49-7/1. Acuerdo de la Sección de arquitectura de la Academia - sobre la propuesta del tándem Álvarez/Zabaleta - con fecha 6 de agosto de 1848. El subrayado es nuestro.

18 Al menos en teoría, tiempo atrás no se concitaba en torno a las pensiones un interés exclusivamente artístico. Así parece deducirse de la sugerencia contenida en aquel seudoreglamento de 1757 en relación a que los pensionados asistan en Roma "a clase de Matemáticas con su aritmética y geometría, Estática, Hidrostática, Hidrometría, Maquinaria, Perspectiva, Trigonometría, Secciones cónicas y Montea". QUINTANA (1983), p. 96. Dado que no era un imperativo sino un consejo, es bastante probable que fueran pocos los que lo siguieran; de todos modos, es un buen indicativo de las intenciones que se tenían al respecto por aquel entonces.

19 La Escuela preparatoria, creada por R.D. de 6 de noviembre de 1848, tendrá una existencia bastante efímera - hasta 1855 . Dicha creación fue alentada desde el propio gobierno, concretamente desde la cartera de Comercio, Instrucción y Obras públicas, de la que era titular entonces Bravo Murillo, aduciendo al respecto, entre otras cosas, razones de economía. Cfr. M. de la Gobernación (1848), XLV; p. 240-241. Así pues, el gobierno, o mejor, las autoridades de Instrucción pública no dejaban de encontrar similitudes - y darles un sentido- entre la Arquitectura y la Ingeniería, mientras la Academia seguía empeñada en no querer verlas.

20 Cfr. LALlAVE, J.J. (1841), Instruccciones sobre la educación de los ingenieros y los arquitectos, Zaragoza. El autor, ingeniero y arquitecto a la vez, fue profesor de mecánica en la Escuela de Arquitectura y director de la misma entre 1875 y 1888. 
revelándose desde hacía tiempo como verdaderos adversarios en el terreno profesional. Téngase en cuenta que la Academia era uno de los productos más elaborados del Antiguo Régimen que el Nuevo miró, al menos inicialmente, con recelo; no en vano el poder burgués confió a los ingenieros y no a los arquitectos la tarea de visualizar y hacer tangible el cambio a través de un vasto programa de obras públicas en las que se cifraban los objetivos previstos de progreso y bienestar social. En suma, con este modelo de pensiones la Academia podía implantar fácilmente sus postulados; y conviene no perder de vista que además lo hacía por medio de unos estudiantes a los que, precisamente en función de sus méritos, podía suponérseles un futuro profesional sumamente prometedor, llegado el cual sería muy probable que perpetuasen aquellos ideales académicos.

Las cosas empezaron a cambiar cuando el gobierno decidió reducir a cuatro años el período de disfrute de las pensiones ${ }^{21}$. Dejando al margen, por su excepcionalidad, los casi doce años que llegó a estar en Roma el primer pensionado, Miguel Fernán$\mathrm{dez}^{22}$, el tiempo de estancia en el extranjero venía siguiendo una tendencia decreciente desde que los estatutos de 1757 fijaron una duración máxima e improrrogable de seis años. La pensión concedida a Aníbal Álvarez en 1832 lo fue ya por un período de cinco años, cuatro fijos más uno de prórroga. A partir de ahora -1850 - se quedaban sólo en cuatro, es decir, tres con posibilidad de otro extraordinario. Por eso, temiendo que una aplicación inmediata de la medida pudiera afectarles, el colectivo de pensionados en Roma de aquel entonces solicita al gobierno la suspensión de la misma. La Academia no parece haber puesto objeción alguna a esta pretensión dado que fue su presidente el que, como era preceptivo, cursó la petición al gobierno en nombre de aquéllos. Pero la disposición no tuvo, como es lógico, efectos retroactivos: Francisco Jareño y Gerónimo de la Gándara, únicos pensionados por la arquitectura en aquellas fechas, pudieron permanecer como tales durante cinco años, aunque no los agotaron en su integridad por otros motivos ${ }^{23}$. Lo que sí parece haber tenido aquella resolución es un carácter premonitorio, puesto que nueve meses después aparecía un reglamento destinado a regular los estudios y movimientos en el extranjero, pero sólo de los pensionados por la arquitectura, sin incluir a los de las demás artes ${ }^{24}$. Ello revela, por un lado, un primer acercamiento legislativo a la cuestión por parte de las autoridades de Instrucción pública, después de haber transcurrido más de seis años desde la promulgación del real decreto de reforma del plan de

21 Así lo hizo por R.O. de 21 de mayo de 1850.

22 Cfr. QuintanA (1983), p. 94.

23 Se les requirió para las tareas docentes, como profesores ayudantes, en 1853.

24 Cfr. el Reglamento a que deberán sujetarse los pensionados españoles para estudiar la arquitectura en el extranjero. Archivo de la Real Academia de Bellas Artes de San Fernando, legajo 49-7/1. Dicho reglamento fue aprobado el 6 de febrero de 1851. No dice nada de los ejercicios de oposición que, en consecuencia, mantendrían la misma línea seguida hasta aquí. 
estudios de la carrera, y, por otro, hasta qué punto tenía prioridad la arquitectura sobre las otras artes en el marco de las aspiraciones en pos del progreso y el desarrollo del país que se había fijado como meta el nuevo régimen burgués. Desconocemos quién o quiénes fueron los redactores del reglamento; es muy probable que el encargo recayese en algún académico que habría tenido que seguir, en última instancia, instrucciones muy precisas de Instrucción pública. Sea como fuere, lo cierto es que la aparición de este reglamento paliaba en cierta medida, al menos en lo que se refiere a la arquitectura, el lamentable estado de abandono en que se hallaba el sistema de pensiones; situación, por cierto, contra la que ese mismo año dirigía una furibunda crítica el pintor y escritor José Galofre. Convencido de que no era posible separar el deficiente funcionamiento de las pensiones del entramado académico que las sustenta, igualmente viciado, bascula buena parte de su argumentación sobre lo que considera una verdadera conculcación de la finalidad primigenia de estas prebendas, puesto que, al considerar "excelente arquitecto" a todo pensionado por la arquitectura por el mero hecho de serlo, el interés de las mismas quedaba cifrado, no tanto en la posibilidad de enriquecer y ampliar los estudios de carrera en el extranjero, cuanto en el hecho de saberse profesionalmente colocado a la vuelta ${ }^{25}$.

Ajustándose al dictado de la última disposición citada, el reglamento contemplaba unas pensiones con una duración inicial de tres años, ampliable a un cuarto si se demostraban méritos suficientes en los anteriores para ganarlo. Según este vademecum, los futuros pensionados pasarían el primer año en Roma estudiando los edificios de la Antigüedad y aquellos otros comprendidos entre los siglos $\mathrm{X}$ y $\mathrm{XV}$, ambos inclusive; en el segundo se trasladarían a Nápoles, Sicilia o Grecia, donde prestarían especial atención a la arquitectura griega; y dedicarían el tercero a viajar por Italia, profundizando en el conocimiento de sus monumentos, sin que se especifique al respecto época o estilo determinado. Al cabo de cada uno de esos años debían remitir a la Academia una serie de trabajos, esto es, de dibujos, que incluirían detalles de edificios y monumentos enteros, además del proyecto de restauración de un ejemplar arquitectónico "reconocidamente bello" al finalizar el tercer año. Por supuesto, todos estos diseños tenían que guardar una determinada escala e ir manchados y acompañados de las correspondientes medidas y acotaciones en metros y pies castellanos $^{26}$. Asímismo, se recomendaba a los pensionados enviar a España durante el se-

25 Cfr. Galofre, J. (1851), El Artista en Italia y demás países de Europa, atendiendo al estado actual de las Bellas Artes, Madrid, p. 172 y ss.

26 El sistema métrico decimal se adoptó en régimen obligatorio en España el 17 de julio de 1849, lo cual quiere decir que en las fechas en que nos movemos aun era demasiado pronto para que hubiese sido asimilado por completo; de ahí que se combine con las medidas de uso común hasta entonces. El pie de Castilla o, lo que es lo mismo, 12 pulgadas o una tercera parte de la vara, equivale a 28 centímetros. Véase la voz "métrico" en AA. VV. (1981), Enciclopedia Universal Ilustrada Europeo-Americana, vol. XXXIV, Espasa Calpe, Madrid, p. 1302 y ss. 
gundo y el tercer año algunos "apuntes" de las arquitecturas bizantina y normanda; dado que no eran trabajos de remisión obligatoria, seguirían siendo propiedad de sus autores después de ser obtenida una copia de los mismos en la Escuela de Arquitectura. Todo estaba preparado, pues, para hacer de estos jóvenes auténticos maestros en el manejo del lenguaje historicista, tolerante y plural, que era el que entonces triunfaba, después de agotado el exclusivismo clasicista grecorromano. Como se ve, hasta aquí apenas se registran variaciones con respecto a la modalidad anterior. Las novedades se reservaban para el año de prórroga. Sería la Academia, cómo no, la que, en vista de la calidad de los envíos anteriores y de la verificación o no de los trabajos voluntarios, propusiera al pensionado ante el gobierno para un cuarto y definitivo año. De ser concedido este, tendría entera libertad para viajar por Francia e Inglaterra a fin de "estudiar la aplicación especial que se ha hecho de los principios artísticos y científicos a ciertas clases de edificios desconocidos de los antiguos y creados por las exigencias de la actual civilización" 27 . Nótese que el referente artístico, exigido antaño en exclusiva, se ve acompañado ahora en igualdad de condiciones por el científico, al entender que sólo así se podría dar respuesta a las necesidades arquitecturales de la sociedad moderna. Italia encarnaba el pasado en arquitectura y ese pasado era, sobre todo, arte; Francia e Inglaterra representaban el presente y el futuro, inconcebibles sin las continuas aportaciones de la ciencia, entendida ésta en sentido lato. Así, de la misma manera que habían variado los principios artísticos en los últimos cien años, era imposible proyectar un hospital a mediados del XIX siguiendo el patrón utilizado un siglo atrás. Se habían producido importantes avances en la ciencia médica con los que la arquitectura debía ir acompasada, lo que implicaba ponerse al día en determinadas disciplinas como, por ejemplo, la higiene. Qué mejor muestra, pues, de ese maridaje perfecto que se invita a descubrir a los pensionados en aquellos países. Aníbal Ảlvarez también estuvo viajando por Francia durante el año de prórroga de su pensión pero, plegándose a las consignas entonces vigentes, habría seguido básicamente el mismo criterio - artístico- que cuando lo hizo por Italia; buena prueba de que obró correctamente en todo momento es que poco tiempo después de regresar a España se le nombró académico de mérito -1839—, en atención, como no podía ser de otro modo, al "celo demostrado en los cuarenta y tres dibujos de monumentos romanos con razonada descripción y la memoria acerca de los materiales empleados en la antigüedad clásica" 28 . Ahora, sin embargo, las prioridades eran otras y el gobierno no podía permitir que España fuese a la zaga de las naciones más prósperas. Tal vez por eso el reglamento exigía a los pensionados

27 Artículo $5^{\circ}$ del reglamento citado en nota 24. Cuando se habla de "aplicación especial [...] de los principios artísticos" entendemos que se alude a una adaptación de los lenguajes arquitectónicos del pasado a los nuevos edificios exigidos por el presente, puesto que en modo alguno hubiera sido viable un vocabulario de nuevo cuño. El subrayado es nuestro.

28 NAVASCUÉS (1973), p. 104. 
del año de prórroga proyectar algún edificio de aquéllos que eran completamente desconocidos en España, "para estar así al corriente de todas las reformas, modificaciones o nuevos métodos que en ellos se hayan introducido" 29 . De este modo, quizá sin pretenderlo, se hacía partícipe a la Arquitectura de esa magna tarea en favor del progreso y el desarrollo del país, que parecía estar monopolizada por los ingenieros. Todo lo cual nos lleva a inferir que lo que realmente se promueve durante este año de prórroga es un desplazamiento del foco de interés tradicional en la arquitectura, el artístico, hacia ese otro de índole utilitaria, más prosaico y pragmático pero también más dependiente del referente científico, proyectado sobre edificios de alcance colectivo.

El nuevo reglamento tuvo aplicación en breve. En efecto, pocos meses después de su aprobación una real orden ${ }^{30}$ asignaba tres nuevas pensiones a la arquitectura que, con una dotación individual de doce mil reales - gastos de viaje aparte-, debían cubrirse a razón de una por año. La primera de ellas se mandó proveer por R.O. de 3 de julio de 1852. Curiosamente, sólo se presentó un aspirante a la convocatoria de oposiciones: se llamaba Francisco de Cubas y González-Montes (1827-1899) ${ }^{31}$ y acababa de terminar en junio pasado sus estudios de carrera, aunque, como era preceptivo para optar a la pensión, todavía no disfrutaba oficialmente de la condición de arquitecto. A diferencia de lo que ocurría con las pensiones de las otras artes, saturadas casi siempre de solicitudes, las de arquitectura no causaban precisamente furor entre los veteranos de la Escuela especial del ramo; será éste un mal endémico en el futuro, hasta el punto de quedar desiertas varias convocatorias a lo largo de la segunda mitad del siglo. La causa habría que buscarla, a nuestro juicio, no tanto en una supuesta falta de capacidad de los potenciales candidatos, puesto que el hecho no era coyuntural sino crónico, cuanto en una especie de inapetencia o indiferencia motivada por el deseo de acceder lo más pronto posible al ámbito profesional y asegurarse así de alguna manera el futuro laboral; de ahí que no sea aventurado afirmar que una

29 Artículo $5^{\circ}$ del reglamento citado en nota 24.

30 Con fecha 22 de agosto de 1851 .

31 Para cualquier información sobre la vida o la obra de este importante arquitecto de nuestro siglo XIX, que llegó a ser alcalde de Madrid (1892), diputado en Cortes y hasta marqués, a pesar de sus "modestos" orígenes, sigue siendo indispensable la consulta del texto, ya clásico por otra parte, del profesor Navascués, citado en la nota 9; aunque las referencias a la pensión de Roma son muy someras, véanse especialmente las págs. 126-130. Consúltese también NAVASCUÉS, P. (1972), "La obra arquitectónica del Marqués de Cubas (1826-1899)", Villa de Madrid, IX, 34, 19-31; y NAVASCUÉS, P. (1993), Arquitectura española (1808-1914). Summa Artis. Historia General del Arte, vol. XXXV, Espasa Calpe, Madrid, p. 298 y ss. Asímismo, puede obtenerse una rápida aproximación a su figura en la publicación aparecida recientemente para conmemorar los 150 años de la Escuela de Arquitectura de Madrid; en ella Cubas aparece entre los "diez nombres-clave" para entender "la moderna arquitectura madrileña". Cfr. AA. VV. (1996), Madrid y sus Arquitectos. 150 años de la Escuela de Arquitectura, Madrid, p. 80-81. 
gran mayoría de los estudiantes de arquitectura de la época veía la profesión como realidad constructiva más que artística, directa y tangible más que posible y etérea.

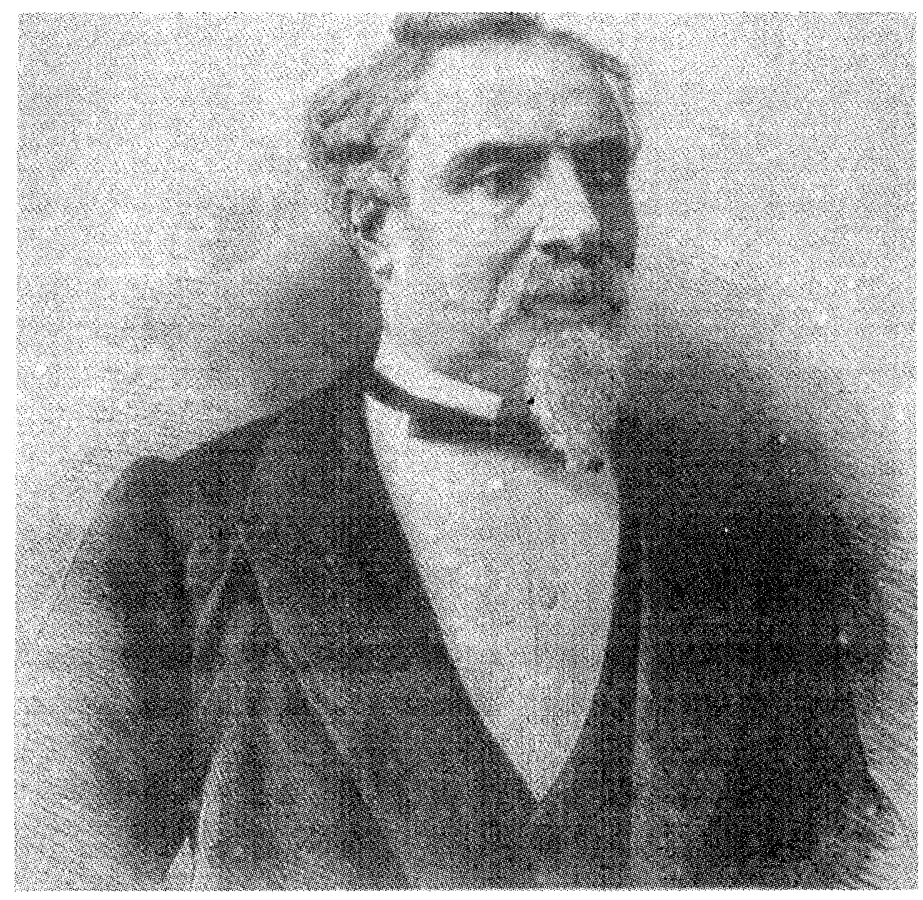

Francisco de Cubas y González-Montes (1827-1899).

Tres fueron los ejercicios de oposición a los que tuvo que someterse Cubas; la suerte determinó en todos ellos el tema o asunto que habría de desarrollar. En el primero le tocó dibujar y lavar - no sabemos si a partir de otro dibujo o de un modelo de yeso- un trozo de adorno de arquitectura de la puerta de San Clemente de Toledo. El segundo consistió en dibujar, esta vez de invención, un cornisamiento corintio para un edificio de primera clase. Y la tercera y última prueba le llevó a proyectar una columna rostral con destino a la plaza principal de un puerto, que él concretó y reconvirtió finalmente en un Monumento a los héroes de Corfú y Lepanto; el proyecto en sí se vio complementado con una memoria facultativa del mismo. Por otra parte, qué duda cabe que el hecho de haber sido el único opositor y no existir competidores restaba severidad al juicio del tribunal, puesto que éste carecía de un referente con el que comparar el mérito relativo del aspirante. Los miembros de di- 
cho tribunal, entre los que se encontraban dos figuras claves de la política educativa de los últimos años, Pedro José Pidal y Alejandro Mon, presentes allí en calidad de individuos de la sección de arquitectura de la Academia, no parecen haber sido ajenos a esta circunstancia. De ahí que al conceder la pensión a Cubas se apresuren a justificar su decisión, señalando que "por el mérito notable de sus trabajos se le podía presumir con mucha capacidad para sostener con dignidad la lucha con otros contrincantes, si se hubiesen presentado" 32 . No conviene olvidar tampoco que un tribunal de esa naturaleza era juez y parte en el caso, toda vez que, como académicos de la sección de arquitectura, sus integrantes serían los primeros interesados en mantener algún corresponsal en el extranjero. Podría decirse que el aval de los estudios de carrera y una actuación sin sorpresas en los ejercicios de oposición eran motivos más que suficientes para obtener el fallo favorable de la comisión evaluadora.

Pero lo que aquí más nos interesa vino después. Francisco de Cubas fue pensionado por R.O. de 10 de enero de 1853. De acuerdo a los plazos previstos en el reglamento de 1851, el 20 de noviembre de 1855 partía de Fomento la orden correspondiente para prorrogar su pensión un año más. La Academia de San Fernando no dudó en elevar al ministerio el informe favorable, después de conocer el "concienzudo estudio" llevado a cabo por el pensionado en relación a la "dificil" restauración del Templo de Júpiter en Pompeya, que había sido el trabajo remitido como envío de tercer año. Pues bien, recuérdese que el reglamento había previsto dedicar ese año extraordinario a viajar por Francia e Inglaterra estudiando aquellos edificios que, desconocidos en España, eran un producto directo de las exigencias devengadas por la moderna civilización, representada precisamente en su grado más elevado por ambos países. Pero el fin ulterior del pensionado era, basándose en esas investigaciones previas, elaborar un proyecto original de la misma índole. Tal fue el cometido asignado a Francisco de Cubas en el último año de su pensión. Año, por cierto, cuyo normal desarrollo se vio interrumpido al presentarse algunos problemas de salud que debieron revestir cierta gravedad, puesto que una R.O. de 18 de septiembre de 1856 concedía al enfermo cuatro meses de licencia para volver a España a recuperarse. Todo hace suponer, no obstante, que el período de restablecimiento fue más corto que el que contemplaba la dispensa; en efecto, la memoria descriptiva del proyecto que ponía punto final a la pensión está fechada el 3 de marzo de 1857.

En torno a este proyecto fin de pensión se concitan una serie de circunstancias que lo convierten en singular. El asunto elegido por el propio Cubas fue una Casa de Maternidad. Lamentablemente, no hemos podido encontrar los cinco planos que lo

32 Documentación relativa a la oposición de Cubas recogida bajo el epígrafe Francisco de Cubas, pensionado por la arquitectura en virtud de oposición, por R.O. de 10 de enero de 1853. Archivo de la Real Academia de Bellas Artes de San Fernando, legajo 49-7/1. 
constituían pero sí la memoria descriptiva ${ }^{33}$, que, desde luego, no tiene desperdicio. En sentido estricto, era la primera vez que se ponía de manifiesto la nueva orientación dada a las pensiones de arquitectura por el reglamento de 1851, en virtud del cual se perseguía el firme compromiso de las mismas con las necesidades de la sociedad contemporánea. Es decir, además de volcarse en el estudio de los grandes edificios del pasado y de su adaptabilidad al presente, se trataba también de no perder de vista la estela de las naciones más prósperas en cuanto a las nuevas tipologías arquitectónicas - y reformulación de otras antiguas- promovidas al compás de los avances sociales, políticos, económicos, científicos y culturales. En este sentido, el amplio ramo de la asistencia social, que alcanzaba desde hospitales hasta casas de beneficencia pasando por un buen número de establecimientos afines, y el sector de los transportes, serán sin duda los que reciban mayor atención. El propio Cubas había previsto para más adelante un par de proyectos consistentes en una Estación central para cuatro líneas generales de caminos de hierro y un Real Colegio central de sordomudos y ciegos, además de un tercero relativo a un Palacio para un museo nacional contemporáneo, es decir, un palacio para la colectividad. Sin embargo, a pesar del entusiasmo que invade al pensionado al referir el carácter novedoso que ha tratado de imprimir a su Maternidad, existían precedentes, relativamente próximos en el tiempo, en los proyectos fin de carrera de los estudiantes de arquitectura. Así, el 8 de septiembre de 1844 era aprobado de maestro arquitecto el joven Domingo Gómez de la Fuente, tras ser examinados por el tribunal los tres planos presentados a la prueba "de pensado" cuyo tema era una Casa de Maternidad ${ }^{34}$.

En el caso de los edificios de asistencia social, los estrictos criterios morales de la mentalidad burguesa parecen haber jugado un papel determinante. En un momento en que lo natural y deseable era que todas las embarazadas diesen a luz en el hogar doméstico, Cubas concibe su Maternidad pensando más que nada en aquellas mujeres involucradas en situaciones de desarraigo y marginalidad social. Es decir, este establecimiento era un producto del régimen burgués que iba dirigido, no tanto a la

33 Se trata de un folleto manuscrito de 16 páginas, las cuales presentan una tonalidad malva y están escritas por ambas caras. La memoria en sí carece de título y va dirigida, cual si de una carta se tratase, al Sr. Presidente de la Real Academia de Nobles Artes de San Fernando. Está agrupada junto a otra documentación bajo un epígrafe que reza D. Francisco de Cubas. Informe acerca de sus trabajos en el año de prórroga de la pensión, que consisten en un proyecto de Casa de Maternidad. 1857. Archivo de la Real Academia de Bellas Artes de San Fernando, legajo. 49-7/1.

34 Cfr. el Registro de las obras de profesores de arquitectura aprobados de maestros arquitectos de 1793 a 1855 . Puede consultarse en la Biblioteca de la Academia de San Fernando, donde está bajo la sign. 3/155; asuntos correspondientes al año 1844, pág. 34. En este registro el tema propuesto aparece como "Casa de Maternidad"; sin embargo, en el proyecto propiamente dicho se califica al edificio de "Hospital de la Maternidad", lo cual revela la existencia de una terminología intercambiable, derivada del hecho de que una maternidad no se concebía como centro específico al margen de los hospitales. A lo sumo sería entendida, y así lo es en este caso, como una modalidad de tipología hospitalaria. 


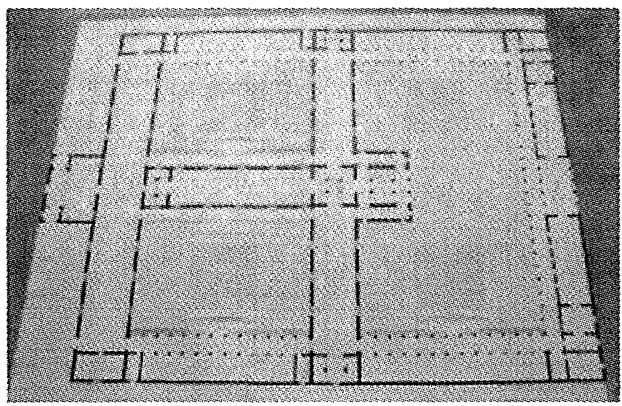

Planta Baja.

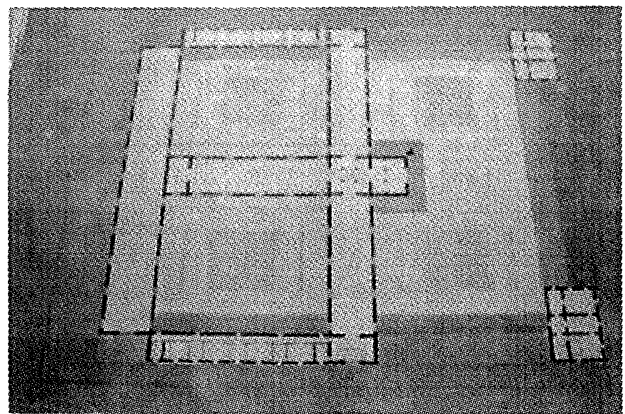

Primera Planta.

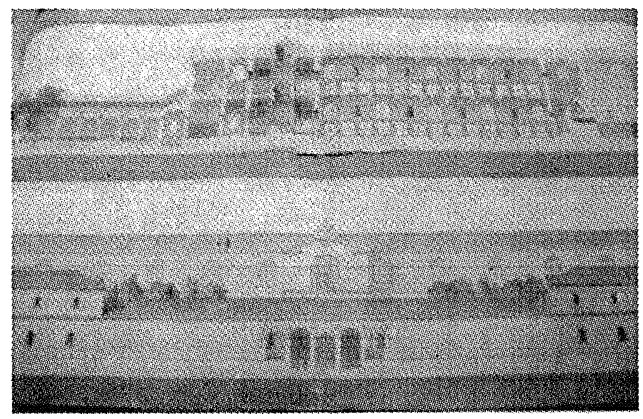

Sección y Fachada principal (detalle central).

Domingo Gómez de la Fuente. Casa-Hospital de Maternidad. 1844. Ejercicio fin de carrera, prueba "de pensado". Único precedente en su género del proyecto de Cubas que hemos hallado en la Academia de San Fernando. La simetría y ortogonalidad de la planta, así como el carácter depurado de la fachada, evidencian el seguimiento de modelos hospitalarios tradicionales. 


\section{JOSÉ MANUEL PRIETO GONZÁLEZ}

mujer burguesa, cuanto a aquella otra que escapaba a su imagen y semejanza, esto es, al prototipo decimonónico de dama correcta, que no era otro que el del "ángel del hogar" como bien ha estudiado Bridget Aldaraca ${ }^{35}$; el parto domiciliario había sido la "norma general" durante siglos, destinándose los centros hospitalarios a parturientas pobres y desamparadas. Ahora bien, en ningún momento se pone en duda que es la sociedad entera, y no sólo las afectadas, la que se resiente de la tradicional carencia de este tipo de centros en nuestro país; en este sentido, la profesora Rosa Ballester ha destacado la importancia de la maternidad como "valor social", enteramente relacionado con aspectos demográficos, políticos, económicos e ideológicos ${ }^{36}$; así, José Luis Peset considera que el mundo victoriano no era partidario de la intervención del Estado en la ayuda al necesitado, pero sí de la acción filantrópica de la clase acomodada ${ }^{37}$.

La defensa del proyecto se hacía, asímismo, desde planteamientos estrictamente médicos. Los hospitales convencionales no reunían las condiciones necesarias para acoger en su seno un cometido específico de esa índole. Rara vez disponían de salas permanentes destinadas al efecto. A menudo se salvaba la coyuntura habilitando para tal fin otras dependencias de signo polivalente. A ello habría que añadir las múltiples deficiencias asociadas a los limitados conocimientos que se tenían antaño en materia de salubridad e higiene. Esta circunstancia, bastante enfatizada por Cubas, no tendría razón de ser en adelante, dado que la última regulación del plan de estudios de la carrera, que databa de 1855, había otorgado a la higiene —en compañía de la óptica y la acústica - rango de asignatura; era el comienzo de lo que, tanto a nivel escolar como profesional, acabará convirtiéndose en una fijación casi obsesiva por parte de los arquitectos del XIX. Por otra parte, era común la creencia de que, para poner fin a cualquier dolencia, los hospitales resultaban más peligrosos que los hogares, por míseros que éstos fueran; en este sentido, J.L. Peset ha señalado que "desde la Edad

35 Cfr. AldARACA, B. (1992), El ángel del hogar: Galdós y la ideología de la domesticidad en España, Visor ed., Madrid. "The Angel in the House" - El ángel del hogar"- es el título de un poema "emblemático" de la literatura victoriana en el que la investigadora Bridget Aldaraca descubre las claves de lo que llama "ideología de la domesticidad" —en relación a la mujer-, tan característica de la cultura urbana burguesa. En su día Virginia Woolf ya vio en el ángel del hogar al prototipo de mujer burguesa decimonónica, que describió como "profundamente compasiva", "absolutamente encantadora", "totalmente abnegada" y, "por encima de todo, [...], pura". Pero Bridget Aldaraca, que analiza en este estudio la plasmación del fenómeno en el caso español a través de La perfecta casada de Fray Luis de León y de algunas novelas de Galdós, va más allá y profundiza en otros aspectos del problema como la dicotomía radical de la existencia social en las esferas de lo público y lo privado, el divorcio, la moral burguesa, las contradicciones inherentes a dicha ideología, etc. ALDARACA (1992), p. 11-16.

36 BALLESTER, R. (1993), "Maternidades y hospitales infantiles (I)", El Médico, 494, 273-278; p. 273. El artículo en cuestión está incluido - con el $\mathrm{n}^{\circ} 19$ - dentro de un coleccionable sobre la Historia de los Hospitales, cuyos coordinadores son Ángel González de Pablo y José Martínez Pérez; pertenece a la Segunda Parte de la serie, en la que se tratan los "Hospitales peculiares".

37 PESET, J.L. (1993a), "El hospital en el mundo contemporáneo (II), El Médico, 487, 197-206; p. 197. 
Media el hospital era considerado como lugar de dolor, muerte y reclusión, y tuvo que pasar mucho tiempo para que perdiera esa fama de pudridero" 38 . En definitiva, al no reunir las condiciones especiales que debían concurrir en toda maternidad, ningún hospital podía equipararse a un centro asistencial ad hoc. Fuera de España existían, no obstante, honrosas excepciones: el Hospital General de Viena, creado en 1784 por iniciativa de José II, incluía cinco secciones médicas, que, al decir de Thompson y Goldin, se presentaban como otros tantos hospitales distintos ${ }^{39}$, entre las que destacaba la Maternidad, que, dirigida por Lucas J. Böer (1751-1835), había sido concebida como "centro de asilo que evitaba los infanticidios"; según parece, de todos los potenciales pacientes del establecimiento, a los que más dedicó sus "desvelos" el emperador fue a las madres solteras ${ }^{40}$. De todos modos, conceptualmente al menos, las maternidades venían de antiguo. Sabemos por Pausanias que en Epidauro, en el territorio sagrado de Esculapio, había una casa donde se asistía a las parturientas. En Roma, en torno al siglo II d.C., el Senado romano habría tenido a su cargo algún establecimiento de esta índole. Después, les perdemos el rastro durante la casi totalidad del medievo, retomándolo en el siglo XIV precisamente en el gran hospital de Paris, provisto ya de una sección materno-infantil; sin embargo, habrá que esperar hasta los años de la Revolución Francesa para encontrar en la capital gala una maternidad propiamente dicha, que, como resultado de la reunión de aquella sección hospitalaria y un hospicio de la Maternidad posterior, se instaló desde 1814 en la abadía de Port Royal. En cuanto a Gran Bretaña, donde las maternidades o lying-inhospitals parecen haber tenido una gestación autónoma como resultado de la aplicación de una serie de leyes de beneficencia ${ }^{41}$, el primer centro de esta naturaleza fue el llamado British Lying-in-Hospital, creado en Londres en 1747; ocho años después, en 1754, aparece el The City of London Lying-in Hospital, que fue "erigido por suscripción" - según leemos en la fachada del establecimiento que recoge un grabado-; la capital británica, en efecto, contó con varias maternidades a partir del siglo XVIII ${ }^{42}$. Así pues, Cubas tuvo ejemplos de sobra para fundamentar su investigación. Por lo que se refiere a España, la Casa de Desamparados de Madrid y las áreas materno-infantiles que se fueron creando dentro de algunos hospitales, constituyen los referentes básicos ${ }^{43}$.

\footnotetext{
38 PESET, J.L. (1993b), "El hospital en el mundo contemporáneo (III), El Médico, 488, 213-218; p. 213.

39 Thompson, J.D. y Goldin, G. (1975), The Hospital: A Social and Architectural History, Yale University Press, New Haven and London, p. 109.

40 LAÍN, P., y otros (1975), Historia Universal de la Medicina, vol. V, Salvat ed., Barcelona, p. 91.

41 BALLESTER (1993), p. 274.

42 Cfr. la voz "maternidad" en AA. VV. (1981), Enciclopedia Universal Ilustrada Europeo-Americana, Espasa-Calpe, Madrid, tomo XXXIII, 956-963, p. 956.

43 Señala Rosa Ballester que "la formación obstétrica de los cirujanos del Real Colegio de Cirugía de San Carlos se llevó a cabo en la Casa de Desamparados de Madrid"; asímismo, respecto a los servicios independientes de algunos hospitales en esta materia, se refiere al Instituto de Terapéutica Operato-
} 


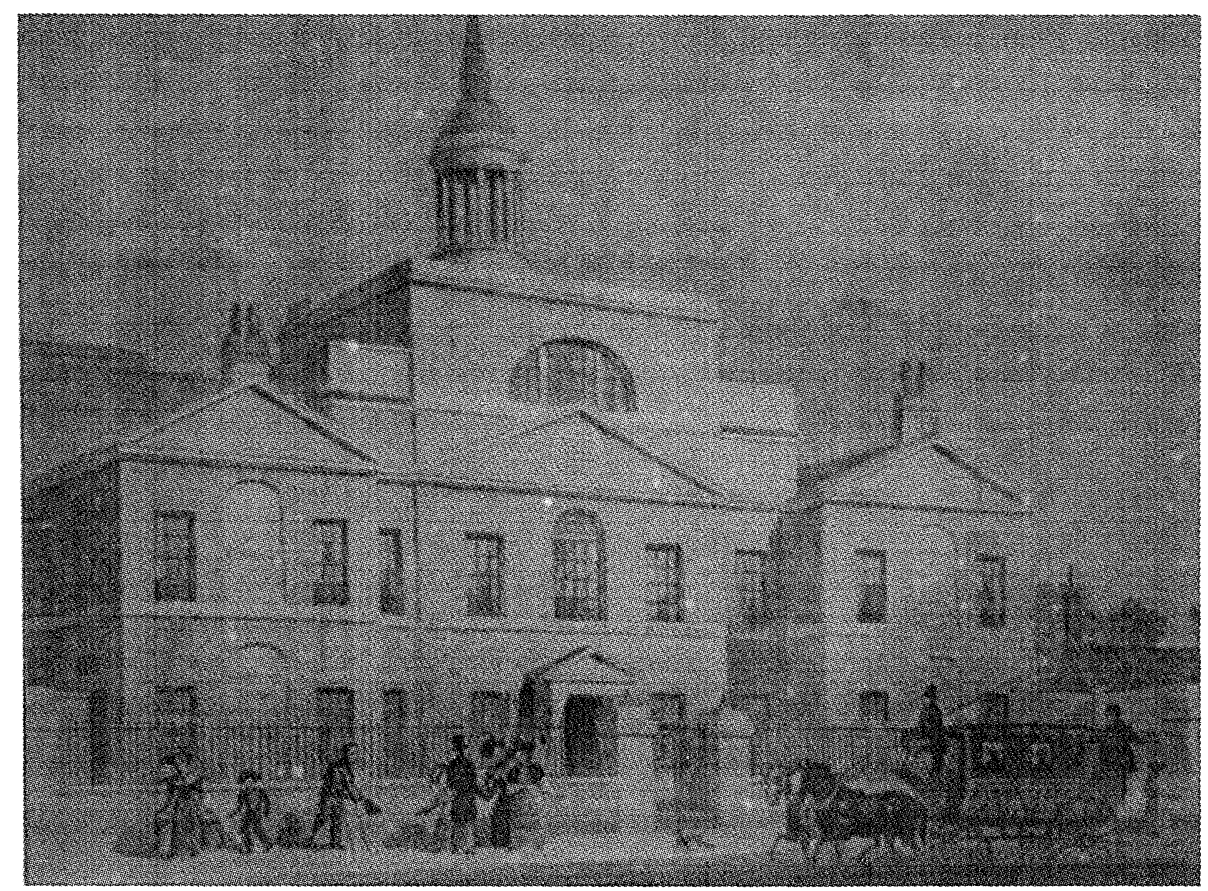

Maternidad de Londres (The City of London Lying-in Hospital, 1754.

Dibujo T. H. Shepherd, grabado por J. Gough. Wellcome Institute of History of Medicine, Londres.

La mujer, la mujer no burguesa para ser más exactos, es aquí el auténtico protagonista. Aun sin perder de vista el contexto socio-histórico en que nos movemos y la consideración que en el mismo se tiene de la mujer, la crudeza - por no decir crueldad- de que son susceptibles hoy los términos empleados por Cubas para referirse a ella, resulta a veces sobrecogedora. Pero lo cierto es que no son sino producto de la "moral inexorable y cruel" —en palabras de Bridget Aldaraca- que campeaba por la sociedad decimonónica. El ideario de la clase social que detenta el poder encuentra aquí una plasmación completa y sin ambages. Para empezar, el mero hecho de tener que recurrir a un hospital para dar a luz convierte a las mujeres que lo hagan en "desgraciadas que legítima o ilegítimamente van a llenar la mayor función de su

ria de Federico Rubio y Galí (1827-1902) como uno de los centros más influyentes. BALLESTER (1993), p. 274 y 276. 
sexo..." 44; no en vano, como apunta Aldaraca, "el valor social de la mujer depende únicamente de su papel de esposa y madre" 45 . Cubas pretende resaltar las ventajas del producto que él ha concebido, poniendo en evidencia al mismo tiempo los fallos del establecimiento que hasta entonces había venido desempeñando esa función. De ahí que censure el modus operandi que ponían en práctica los hospitales en estos casos: problemas en la admisión, dificultades para que las mujeres puedan "ocultar su falta a los ojos de la generalidad", reconocimientos "vejatorios" llevados a cabo por distintas personas, etc. De todo lo cual resulta que muchas de ellas prefieren "ejercer su criminal acción sobre el ser que concibieron -es decir, abortar-, exponiéndose ellas mismas á una muerte prematura y desgraciada", antes que la "vergüenza" pública. Pero, según se deduce de sus palabras, eso no es lo peor. Lo más lamentable es que, obrando así, "privan [...] a la sociedad de seres que pudie-

44 Archivo de la R. Academia de S. Fernando, legajo 49-7/1 (1857), D. Fco. de Cubas. Informe..., p. $3 v$.

45 ALDARACA (1992), p. 17. En la sociedad del siglo XIX la maternidad era la primera y más importante responsabilidad encomendada a las mujeres. Además de una "responsabilidad sagrada" era también "la esencia de la feminidad", hasta el punto de que "la mujer sin hijos no es una verdadera mujer". La "pasión maternal" era, igualmente, la "característica femenina por excelencia", que definía a su vez a la mujer como el sexo que "siente", frente al hombre, garante del sexo que "piensa", que razona. ALDARACA (1992), p. 30 y 168-9.

Pedro Felipe Monlau, higienista español del siglo XIX, situaba el centro fisiológico de la mujer en la matriz, no en el corazón, y no dudaba en afirmar que "el útero hace que la mujer sea lo que es"; no extraña pues que piense que "a las mujeres no se les debiera permitir el matrimonio sin que previamente contase su aptitud fisica para el parto", o que oponga el binomio mujer-madre a una (mujer) obrera. Para el colectivo médico también estaba claro que "su potencial reproductivo la define y la limita a un papel social único, el de la maternidad”. ALDARACA (1992), p. 56.

Ahora bien, la maternidad no podía tener lugar a cualquier precio; debían seguirse unos cauces morales que apelaban, en primer lugar, a la consecución de esa función dentro del matrimonio. Cualquier desviación en ese sentido podía acarrear efectos perniciosos para la infractora; así nos lo hace ver Galdós en Fortunata y Jacinta, donde "la esterilidad de Jacinta triunfará sobre la fecundidad de Fortunata cuando el poder de la clase burguesa haga posible que la mujer de Juanito Santa Cruz se apropie el hijo que ella misma no es capaz de producir". Y es que la soltería, triplemente definida como "enfermedaddecrepitud-promiscuidad", se consideraba un estado "estéril, malsano y antinatural"; así lo pregonaba, no sólo la doctrina católica, a través de la condena que hacía de toda actividad sexual al margen del matrimonio, sino también las instituciones de salud pública, incapaces de controlar las enfermedades venéreas. Todo lo cual puede explicar el espectacular auge que empezó a tomar en aquella época el movimiento que aunó a higienistas y moralistas para poner coto a estos problemas; no por casualidad, pues, se perciben los ecos de esta ofensiva en el proyecto de Cubas. Por lo demás, era común la opinión de que "una mujer recta no conoce el deseo sexual"; lo contrario sería una manifestación "indecorosa", susceptible de revelar síntomas de "ninfomanía" o "furor uterino", en suma, "perversión sexual". Los especialistas estaban convencidos de que la mujer "satisfacía cualquier deseo sexual que pueda sentir a través del embarazo y el parto", de tal forma que "la necesidad de tener hijos es una de las pocas pasiones legítimas permitidas a la mujer"; la sexualidad femenina era inseparable de la función reproductora. ALDARACA (1992), p. 19, 174, 58 y 61. 
ran serle útiles —como fuerza de trabajo, se entiende-y jamás indigentes" 46 . La mejor manera de evitarlo consistía en garantizar a esas mujeres que su "falta" sería un "secreto inviolable" para el personal del centro que tuviera acceso a ellas. Y qué mejor garantía que limitar ese acceso a las hermanas de la caridad que habrían de regentar el establecimiento; téngase en cuenta que la enfermería aun era un cuerpo auxiliar en ciernes por aquel entonces ${ }^{47}$. Los criados sólo podrían franquear el umbral de las habitaciones cuando las pacientes no se encontraran en ellas. Por si esto no bastara, el proyecto incluía también "salas de contraseñas" como espacios de tránsito entre la zona pública y la, más que privada, secreta ${ }^{48}$. Es decir, el proyecto arquitectónico de Cubas se amoldaba a la discreción requerida por la situación, criterio que ya habían observado, por ejemplo, la Maternidad de Göttingen (1785), pri-

46 Archivo de la R. Academia de S. Fernando, legajo 49-7/1 (1857), D. Fco de Cubas. Informe..., p. 4v. Idénticos intereses demográficos había aducido en su día José II en relación a la Maternidad del Hospital de Viena; es más, allí y entonces (1784), la ley penaba el aborto con la muerte de la mujer. THOMPSON \& GOLDIN (1975), p. 109.

47 Fue una dama victoriana, Florence Nightingale, la que favoreció el desarrollo de la enfermería por aquellas fechas, al emprender una campaña en favor de los heridos de la Guerra de Crimea (185556); años después, en 1859, la creación de la Cruz Roja -tras la batalla de Solferino- coadyuvó enormemente a la instauración de la enfermería moderna. Poco a poco, las enfermeras laicas irán sustituyendo a las monjas en estos menesteres. Pero la importancia de Nightingale en este contexto trasciende con creces ese hecho, acaparando también nuestra atención por haber sido una "notable defensora del moderno higienismo y, como tal, una ferviente hipocrática"; José Luis Peset ha destacado su preocupación por aspectos como la ventilación y la limpieza en edificios de este tipo, así como su interés por las teorías ambientalistas de los anticontagionistas, "que veían posibles transmisores entre lugares y personas a través del aire"; su idea última sería lograr que los hospitales se pareciesen lo más posible al hogar materno. PESET (1993a), p. 198-9. La que luego fue conocida como "Sala Nightingale", cuya localización ideal sería la dispuesta en hospitales construidos en forma de pabellones, se caracterizó por presentar paredes de colores alegres, amplios ventanales de traza gótica, orientación norte-sur para mantener una insolación duradera, ausencia de ángulos y rincones para evitar la acumulación de miasmas..., en definitiva, un espacio de aire puro; y es que la relación entre suciedad y enfermedad había quedado demostrada empíricamente. PESET (1993a), p. 205-6.

48 Lo público y lo privado "son percibidos como espacios sociales separados, teóricamente complementarios e interdependientes, pero a menudo representados como antagónicos y exclusivos". En este sentido, la percepción de la esfera pública sería "tan materialista y amenazadora" que provocaría una "idealización" de la privada. AlDARACA (1992), p. 43.

Por otra parte, resulta curioso comprobar como el "todopoderoso 'qué dirán'“ es capaz de asumir una lectura arquitectónica. Y es que el secreto era, en este caso, la única protección que tenía la mujer contra una opinión pública destructiva que, en su calidad de "máxima autoridad social", era un "poder invulnerable, no identificable, anónimo. [...] Libre de crear y destruir reputaciones, el 'qué dirán' no es susceptible de ser controlado". Lo cual revela que la esfera pública era un terreno que sólo el hombre dominaba y, en consecuencia, "la mujer que deja el hogar pierde como castigo el derecho de protección de su marido". ALDARACA (1992), p. 176 y 53. 
mera en su género del ámbito germano, y la del Hospital de Viena ${ }^{49}$. Así pues, podría decirse que la inmensa mayoría de las mujeres que acudieran a la Maternidad serían casos perdidos en cuanto a la consecución personal de ese ideal de dama correcta; consumado el delito, de la naturaleza que fuera, el único consuelo que les quedaba a los individuos de la clase burguesa era saber que a través de establecimientos como éste podían salvarse brazos para trabajar.

Mediante una propuesta como la que avala su trabajo, Cubas trata de impedir que se siga especulando con la "desgracia". El suyo es un edificio de "caridad cristia$n a$ " en el que no se pueden escatimar gastos; quedaba exento, por tanto, de sujeciones rígidas al principio de economía que debe observar toda buena arquitectura. Por otro lado, fiel reflejo de la división en clases de la sociedad, la Maternidad aparece estructurada también en distintos sectores que guardan relación con la solvencia económica de las internas así como con su situación ante la justicia. De este modo, las mujeres que se amparaban en la condición caritativa del establecimiento por no tener recursos para sufragar su estancia en él, estaban separadas de aquellas otras que sí podían hacerlo y que acudían allí únicamente "por más seguridad" de la que les brindaba el parto en casa; el hecho de retribuir al centro por estos servicios les garantizaba en exclusiva unas comodidades equiparables a las que podrían disfrutar en su propio hogar - salas de recepción, biblioteca, salón de recreo, etc.- - Hay, no obstante, un reconocimiento explícito acerca del escaso número de señoras que preferirían este centro a su casa particular para dar a luz ${ }^{50}$; serían reacias a acudir a un establecimiento de estas características porque, de cara sobre todo a sus iguales, podría resultar degradante verse entremezcladas en un colectivo de parturientas de toda clase y condición. Apartadas de unas y otras estaban aquéllas que tenían causas pendientes con la justicia y debían permanecer, en consecuencia, bajo vigilancia ju-

49 En efecto, dado que a la Maternidad del Hospital de Viena podían acudir también las prostitutas, se trató de salvaguardar su intimidad en la medida de lo posible; así, por ejemplo, la localización estratégica de esa sección en el complejo hospitalario permitió habilitar en sus inmediaciones un paseo privado y protegido, ajeno por completo a las demás secciones, donde esas mujeres pudieran tener unos momentos de recreo y esparcimiento, eso sí, cubierto su rostro convenientemente por un velo y provistas siempre de una nota identificativa por si acaecía una muerte súbita; dicha iniciativa se inspiraba, según parece, en otra análoga anterior puesta en marcha en la Maternidad de Göttingen. THOMPSON \& GOLDIN (1975), p. 113. En relación a este último establecimiento véase JETTER, D. (1966), Geschichte des Hospitals, vol. I, Wiesbaden.

50 "La esencia de la mujer ideal no es que sea discreta, hacendosa, ahorradora [...], sino que encarne todas estas virtudes solamente en el hogar. La mujer es definida fundamentalmente no en sus vertientes ontológica y funcional, sino por el espacio que ocupa. La frontera de su existencia como mujer virtuosa empieza y termina en la puerta de su casa..." Y es que "la mujer (esposa) fuera de su casa se convierte en una mujer pública..., [y] la mujer no encaja en la vida pública". En España, su deber era seguir "el dictamen de la tradición cultural española que reza: "La mujer honrada, pierna quebrada y en casa", refrán tan ingenuamente coercitivo en comparación con su equivalente en inglés: "A woman's place is in the home' (el lugar de la mujer es el hogar)". ALDARACA (1992), p. 22, 24, y 181. 
JOSÉ MANUEL PRIETO GONZÁLEZ

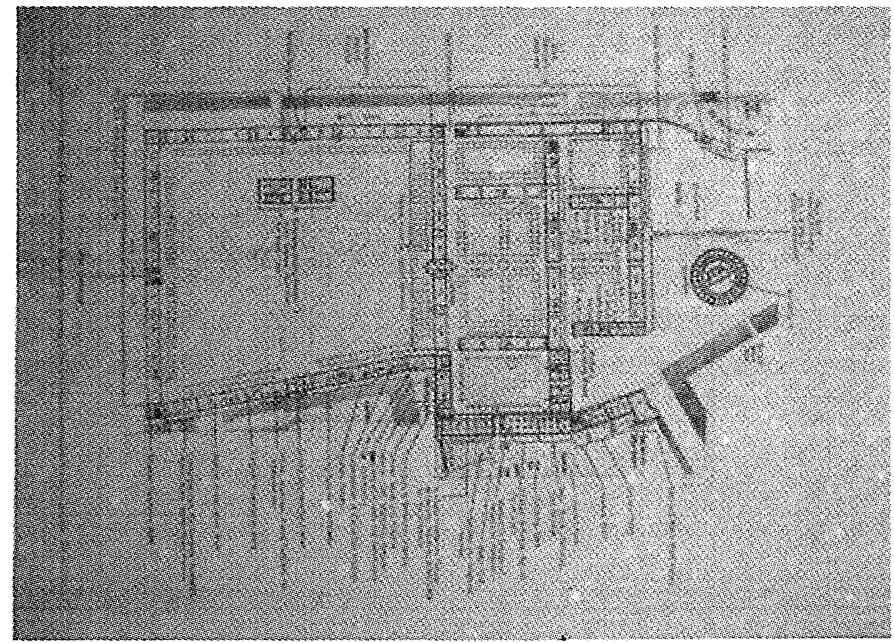

Planta del Hospital General de Viena (1784). La maternidad se localiza en la parte superior derecha.

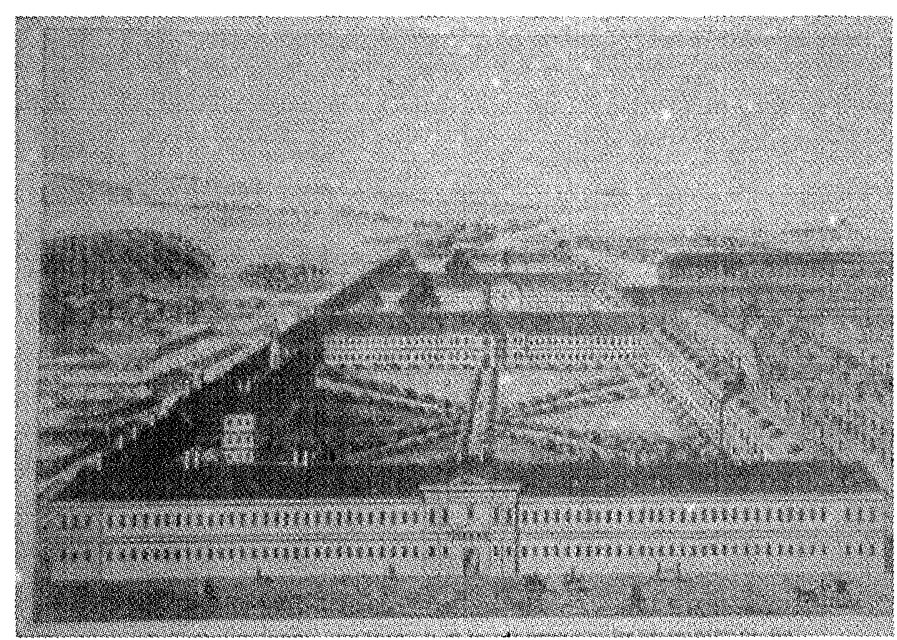

El Hospital General de Viena (1784) a vista de pájaro, en un grabado de hacia 1834. La puerta de la derecha conduce a la sección de maternidad. 
dicial. Asímismo, dado que el "estado de preñez" podía verse complicado en ocasiones por mor de alguna enfermedad, Cubas había dispuesto subdividir en dos secciones - para los casos en que se contemple esa circunstancia y para los que no-el grupo potencialmente más numeroso, esto es, el de las mujeres que, sin cortapisas penales de ningún tipo, quedaban a merced del auxilio altruista del establecimiento. Se hacía preciso neutralizar cualquier enfermedad "antes de que el desgraciado ser que [las mujeres afectadas] alientan en su seno, venga al mundo con el germen de males que pudieran hacerle aun más desgraciado y a la sociedad cargarla con el peso de miembros inútiles..." 51 .

La traducción arquitectónica del planteamiento anterior se plasma en una serie de salas relativamente pequeñas, con las que se persigue optimizar las condiciones higiénicas y hacerlas lo más homogéneas posible en todo el centro. Francisco de Cubas opta, así, por una especie de dependencia-tipo de ocho camas, que permite, además, que las embarazadas que presenten dolencias asociadas sean agrupadas atendiendo, no ya sólo a ese estado general de enfermedad, sino incluso a patologías específicas, consideradas individualmente o en compañía de otras análogas - de convivencia compatible52 - De todas formas no era éste el único modelo de habitación - las había también de una sola cama ${ }^{53}$-, aunque sí el mayoritario. El proyecto incluía un total de ciento setenta y dos camas, "número no nacido del capricho sino deducido de datos estadísticos" 54 . Pero la adopción de principios higiénicos iba mucho más allá. No en vano, en el ánimo de Cubas estaba que su proyecto observase "todos los preceptos de la higiene". Era como si en ese aspecto concreto se resintiese sobrema-

51 Archivo de la R. Academia de S. Fernando, legajo 49-7/1 (1857), Fco. de Cubas. Informe..., p. 6r.

52 Así, por ejemplo, dispone dos habitaciones para las que tengan escarlatina, sarampión y viruelas; otras dos para las que presenten enfermedades de la piel no febriles; el mismo número para las afectadas de sífilis; dos también para las enfermas de cólera epidémico, disentería y dolencias afines; ídem para las que padezcan fiebre no epidémica, etc. Archivo de la R. Academia de S. Fernando, legajo 49-7/1 (1857), Fco. de Cubas. Informe..., p. 6v. y 7r.

53 Destinadas a casos especiales: hemorragias, convulsiones, fiebres tifoideas, dementes, etc. Archivo de la R. Academia de S. Fernando, legajo 49-7/1 (1857), Fco. de Cubas. Informe..., p. 6v.

54 Curiosamente, se ve obligado a recurrir a datos extraídos de Francia porque las autoridades españolas ignoran los relativos a su jurisdicción y los médicos de nuestro país eluden — según dice, "por excesiva modestia" - hacer públicas las investigaciones que realizan a título personal. De acuerdo con esos datos, en Francia se habrían registrado, durante un período de 10 años y sobre una población de 30 millones de habitantes, más de 10 millones de nacimientos, de los cuales 9.031 .908 serían hijos legítimos, 703.663 lo serían naturales - fuera del matrimonio- y 336.281 habrían sido abandonados. Pues bien, Cubas probaba la necesidad de estos establecimientos suponiendo - sobre la media anual de las cifras anteriores - que en ellos verían la luz la mitad, al menos, de los hijos naturales - 35.183- y la totalidad de los abandonados - 33.628 -; a estas cantidades añadía el 10\% de su suma total en concepto de "crímenes" o abortos voluntarios que podrían evitarse: el resultado final ascendía a 75.692 criaturas. Por lo demás, calculaba en torno a dos meses el período medio de estancia de las mujeres en la maternidad. Archivo de la R. Academia de S. Fernando, legajo 49-7/1 (1857), Fco. de Cubas. Informe..., p. 7r. y 7v. 
nera la ventaja que le sacaba a la arquitectura española la de las naciones más avanzadas; ventaja, por cierto, que este último año de pensión tenía por objeto combatir. De cara a la consecución de estos preceptos procede, cómo no, a hacer aplicación de las ciencias físico-matemáticas. Así, contraviniendo una ley no escrita en la tipología hospitalaria, relativa a la distribución espacial, evita que los dormitorios comuniquen directamente con una galería general. De no haberlo hecho así se habría vuelto a repetir el efecto dañino de las corrientes de aire incidiendo sobre las pacientes, toda vez que, al abrir las puertas de las habitaciones, se produce el contacto entre dos masas de aire a diferente temperatura - más elevada en las salas y menos en la galería- que es el que provoca ese inconveniente. Para subsanarlo introduce una galería intermedia y dispone las puertas de los dormitorios no paralela sino perpendicularmente a las de la galería principal.

Adelantándose a las experiencias y objetivos de la "Sala Nightingale" 55 , Cubas se interesa también por las condiciones de aireación de las habitaciones. En tal sentido calcula su cubicación y la pone en relación con el índice de vapor de agua producido por la transpiración humana ${ }^{56}$. El fin último era que las internas respirasen aire limpio permanentemente. Para ello, la renovación del aire debía procurarse "a medida de su viciación". Los gases más pesados, localizados en la parte baja de los dormitorios, serían expulsados mediante ventiladores y corrientes de agua a nivel del pavimento; los más ligeros, concentrados arriba, por medio de ventiladores igualmente pero en este caso próximos al techo. Las ventanas, con una altura equivalente a dos tercios del muro en que se abrían, ocupaban la parte alta de éste, siendo su borde superior tangente con el techo; contaban con dos aberturas de disposición horizontal, independientes una de la otra, e irían provistas de doble juego de vidrieras. Se trataba, de ese modo, que, si al encontrarse abiertas se producía cualquier corriente de aire, ésta discurriese por la zona alta de las habitaciones, sin afectar a las internas, y que los gases más ligeros que el aire pudieran disiparse con facilidad. Asímismo, un

55 Véase nota 47.

56 Casi con la misma minuciosidad científica y el mismo afán higienista que presentarán, ocho décadas más tarde, buena parte de los proyectos de arquitectura escolar del GATEPAC, Cubas se hace eco aquí de una serie de datos extraídos de los tratados de higiene al uso - en especial del de Mr. Levy Michel-, según los cuales la transpiración diaria de un hombre produce una cantidad de vapor de agua que oscila entre los 800 y 1.000 gramos, a razón de unos 38 gr. por hora. Suponiendo el aire a la mitad del grado de saturación y a una temperatura de $15^{\circ}$, concluye que serían necesarios alrededor de $6 \mathrm{~m}$. cúbicos - por hora e interna- para disolver esos 38 gr. de vapor de agua. Pues bien, el proyectado dormitorio-tipo de ocho camas mide, con su pieza adyacente, $640 \mathrm{~m}$. cúbicos, rebajando $16 \mathrm{~m}$. por el volumen de las pacientes, camas, mesillas de noche, etc. Archivo de la R. Academia de S. Fernando, legajo 49-7/1 (1857), Fco. de Cubas. Informe..., p. 10v. y $11 \mathrm{r}$. 
apropiado sistema de calefacción ${ }^{57}$ permitiría a los facultativos disponer en las salas la temperatura e hidratación del aire más adecuadas a cada momento.

La discreta decoración prevista para los dormitorios evidenciaba en su diseño la atención prestada, no sólo a la higiene, sino también a las prioridades devengadas por el carácter funcional del establecimiento, que limitaba toda pretensión artística. Así, en lo tocante al primer aspecto, redondea los ángulos diedros para evitar que se acumulen en ellos los gases nocivos, al tiempo que suprime todos los relieves que pudieran ser un obstáculo a su salida; además, dando inicio a una práctica comúnmente seguida hoy en casi todos los centros sanitarios, aplica a las paredes una tonalidad verde muy clara y homogénea que apenas absorbe rayos luminosos y los que refleja no afectan para nada al sistema ocular; finalmente, prescinde de todo aquello que, "directa ó indirectamente, pueda alimentar la idea de la muerte que tan inminente creen las mujeres" 58 . Nada es, pues, producto del capricho. No existe especulación ornamental. Todo tiene, en suma, un por qué y un para qué. Por lo demás, Cubas acude a materiales de construcción tradicionales. En el interior, nuevamente por razones higiénicas, tenía previsto emplear con profusión la madera: pisos y lechos serían de este material, evitaba así que las habitaciones fuesen susceptibles de sufrir las alteraciones atmosféricas del exterior ${ }^{59}$. En el dormitorio-tipo de ocho camas, éstas, separadas de los muros, quedarían dispuestas en dos filas de a cuatro, mediando $2 \mathrm{~m}$. entre ellas y $1,40 \mathrm{~m}$. entre las camas. Es bastante probable que el enorme interés de Cubas en que su proyecto se adapte a los principios higiénicos descritos esté relacionado con los avances médicos afines que se habían registrado diez años antes; concretamente nos referimos a los descubrimientos de Ignaz Philipp Semmelweiss (1818-1865) sobre la génesis y profilaxis de las infecciones puerperales, verificados en las salas de obstetricia del Allgemeines Krankenhaus de Viena. En efecto, corría el año 1847 cuando este joven médico húngaro demostró con toda claridad la "contagiosidad de la fiebre puerperal que asolaba entonces las maternidades", indicando que eran las manos del médico las que actuaban de transmisor de las infecciones. De ahí que diera instrucciones precisas a todo el personal de la clínica donde trabajaba para que "se lavasen y cepillasen las manos con hipoclorito de

\footnotetext{
57 Su propuesta al respecto sería resultado de la suma de varios sistemas modificados; en este sentido, dice seguir los de Darcet, Peclet, Félix Leblanc, Bonnemain y, sobre todo, los últimos escritos sobre la materia de M. Boudin. Archivo de la R. Academia de S. Fernando, legajo 49-7/1 (1857), Fco. de Cubas. Informe..., p. $11 \mathrm{v}$.

58 Archivo de la R. Academia de S. Fernando, legajo 49-7/1 (1857), Fco. de Cubas. Informe..., p. 12v.

59 La madera, además, se había revelado como un material que favorecía la curación de los enfermos. El médico militar norteamericano James Tilton advirtió que "los enfermos asistidos en graneros o tiendas curaban mejor que los llevados a hospitales de piedra tradicionales", lo que le indujo a "idear la construcción de barracones de madera unidos en forma de $H$ ", en los que se lograron "sorprendentes tasas de curación". PESET (1993b), p. 214.
} 
calcio después de las autopsias y antes de explorar a cada parturienta" 60 . Todo apunta, en este sentido, a que fueron precisamente los estragos causados por la fiebre puerperal los que motivaron la aparición de las maternidades modernas a partir de mediados del siglo XIX, unas veces aislando sus servicios de las demás secciones hospitalarias y otras dándoles autonomía arquitectónica, es decir, desgajándolos de los hospitales. Qué duda cabe que el parto domiciliario también llevaba asociados problemas de índole higiénica; resulta significativo, en este sentido, un grabado satírico de William Hogarth (1697-1764), en el que se ve a una parturienta rodeada de comadronas en una habitación, mientras, en primer término, una multitud de roedores se encuentra al acecho. Será en el último tercio del siglo XIX cuando los avances en el campo de la Obstetricia y la Ginecología operatoria, posibilitados por la revolución listeriana en el marco de la Cirugía general, y sobre todo la aparición de la Tocoginecología como especialidad, favorezcan, según Rosa Ballester, "una nueva concepción de la atención al parto", que tendrá también implicaciones en el terreno arquitectónico ${ }^{61}$.

Nos es imposible conocer las trazas exteriores del edificio y, a través de ellas, su adscripción estilística; pero no sólo por no haber tenido acceso a los planos del pro-

60 LAín y otros (1975), vol. V, p. 318-319; vol. VI, p. 176. Téngase en cuenta que el descubrimiento de Semmelweiss trasciende con creces el caso específico de las parturientas, toda vez que implicaba al conjunto de las infecciones sépticas de las heridas, es decir, permitía controlar "el problema más agudo de la cirugía de entonces, el problema de las heridas". Por otra parte, parece ser que el hallazgo tuvo lugar sin conocer ciertos antecedentes. Así, Edward Strother (1675-1735) ya había advertido en 1716 sobre la naturaleza contagiosa de la fiebre puerperal que habrá de causar verdaderos estragos entre las madres del siglo XVIII. Pero fue un médico de Manchester, Charles White (1728-1813), quien, anticipándose setenta y cinco años a los trabajos de Semmelweis, "redujo considerablemente la mortalidad materna con su insistencia sobre la limpieza escrupulosa de cuanto estuviese en contacto con mujeres recién paridas, así como promoviendo el mayor nivel de la higiene de las salas", lo que le llevó a proponer, entre otras cosas, que se evitara el hacinamiento de las pacientes y se cambiara con regularidad la ropa de las camas. Sus teorías quedaron recogidas en el libro Treatise on Management of Pregnant and Lying-in Women (1773). El irlandés Sir Fielding Ould (1710-1789) también aportó nuevos avances a través de su Treatise on Midwifery (1742) y el americano Oliver Wendel Holmes (1809-1894) publicó en 1843 una comunicación sobre la contagiosidad de la fiebre puerperal, "planteando en las conclusiones que el médico que tuviera que ocuparse de casos obstétricos se abtuviese de participar en la autopsia de enfermas fallecidas de fiebre puerperal o, en caso de haberlo hecho, se lavara a fondo, cambiando todas sus prendas de vestir" y evitara, en cualquier caso, intervenir en nuevos partos durante las veinticuatro horas siguientes. En el ámbito centroeuropeo, sin embargo, se siguió atribuyendo la génesis de estas fiebres e infecciones a factores de tipo meteorológico o atmosférico tales como la humedad, la temperatura, la presión, la dirección de los vientos, etc. Con su descubrimiento, Semmelweiss fue el primero en demostrar allí la "inconsistencia de esta ficción meteorológica". No obstante, muchos colegas no aceptaron el hecho de que la enfermedad fuese transmitida, y mucho menos que fuera el médico el agente transmisor en la mayoría de los casos. Serán Pasteur y Lister los que tomen el testigo —con éxito- en esa dirección. Por lo demás, Semmelweiss dirigió, tiempo después, la Maternidad de San Roque en Pest. LAín y otros (1975), vol. V, p. 90, 122, 281 y 318-320; vol. VI, p. 302 y 355-356.

61 BALleSTER (1993), p. 273. 
yecto sino también porque la memoria carece de cualquier referencia sobre el particular, debido tal vez a las motivaciones - poco deudoras de lo artístico- que explicaban la intencionalidad última del trabajo del año de prórroga. No obstante, en atención al vasto repertorio clasicista - tanto del mundo antiguo como del quattrocento- que habría conocido de cerca en Italia y a lo que fueron sus preferencias iniciales a este respecto en el ámbito profesional ${ }^{62}$, no sería descabellado suponerle al proyecto unas formas de raigambre clasicista o, más concretamente, neorrenacentistas. Por lo demás, si, como es de suponer, llegó a conocer las maternidades inglesas durante el año de prórroga, es probable que el diseño del edificio sea deudor en alguna medida del que ofrecían los establecimientos londinenses a que nos hemos referido anteriormente.

A diferencia de los envíos de los años anteriores, que pasaban a ser propiedad de la Academia de San Fernando, el trabajo del año de prórroga de la pensión quedaba en poder de su autor, una vez recibida la pertinente aprobación de la Academia. Pero el mejor estímulo que podían recibir esos jóvenes en un momento tan crucial para su futuro profesional era, precisamente, el espaldarazo gubernamental, canalizado a través de la adquisición de dichos trabajos por una suma generosa que recompensase de alguna manera aquellos años de estudio en el extranjero. Así fue, en efecto, como procedió el gobierno desde entonces. Ahora bien, no era lo mismo comprar un lienzo o una escultura que los planos de un edificio; las primeras eran piezas con un valor intrínseco autónomo puesto que estaban completamente concluídas; los planos de un edificio, en cambio, no eran más que la plasmación gráfica de una idea arquitectónica cuya potencialidad artística plena quedaba a expensas de la materialización del proyecto. $\mathrm{Y}$ aunque el gobierno era el primer interesado -o al menos aparentaba serlo- en seguir de cerca a nuestros vecinos franceses e ingleses en materia arquitectónica, no disponía de recursos para respaldar de forma sistemática la concreción práctica de esas composiciones supuestamente vanguardistas. Lo cual ponía al descubierto una vez más las diferencias entre la arquitectura y las demás bellas artes. Pues bien, la memoria del proyecto de Cubas está firmada y fechada el 3 de marzo de 1857. En noviembre de ese mismo año el autor remite una instancia al gobierno solicitando que se le "indemnice" por el trabajo, del mismo modo que se había hecho con sus colegas de otras artes. La Dirección general de Instrucción pública responde entonces pidiendo a la Academia un informe, relativo, no tanto a las virtudes artísticas del proyecto, cuanto al affaire de la retribución. Del dictamen se ocupó la propia sección de arquitectura de la institución y no, como hubiese sido de esperar, una

62 Aunque la faceta de arquitecto del historicismo neogótico sea tal vez la más conocida en Cubas, por lo "febril" de la misma así como por el hecho de coincidir sobre todo con su etapa de plena madurez -que llega con la Restauración-, en nada desmerece los primeros trabajos en el terreno profesional, en los que Cubas sigue los pasos de la última generación académica; de ahí el estilo "italianizante y tardoneoclásico" de los mismos. En ellos - dice Navascués - "se muestra como un fiel seguidor de Colomer, del Colomer del palacio del marqués de Salamanca". NAVASCUÉS (1973), p. 126. 
comisión mixta formada por individuos de las distintas secciones; de ahí que cuando aquélla se pronunció al respecto, todo fueron laureles para Francisco de Cubas. El informe, emitido en enero de 1858, incidía en la notoriedad de los conocimientos higiénicos y mecánicos aplicados por el pensionado en su proyecto de maternidad, que eran precisamente los que "tanto distinguen y caracterizan los edificios de la época actual en las naciones más cultas" 63 . Los miembros de la sección estiman, por ello, que el trabajo de Cubas "vale por lo menos tanto como una obra de las demás artes" y, en consecuencia, sugieren que se indemnice al interesado con la misma cantidad con que fueron recompensados los pensionados por la pintura, la escultura y el grabado que habían concluído también por entonces sus trabajos. Dicha cantidad ascendía a 30.000 reales vellón. Sin embargo, amparándose exclusivamente en consideraciones de tipo utilitario ${ }^{64}$, Fomento desestimaba la sugerencia contenida en el dictamen de los académicos, limitando la indemnización a 12.000 reales, además de cursar una recomendación de la obra al Ministerio de la Gobernación. Así pues, la arquitectura iba asumiendo otro cariz, distinto del tradicional — ligado a las bellas artes-, a los ojos de los poderes públicos y, en último término, de toda la sociedad.

63 Informe fechado el 14 de enero de 1858. Archivo de la R. Academia de S. Fernando, legajo 49-7/1.

64 “...el mencionado proyecto no puede ser utilizado por este Ministerio..." —el subrayado es nuestro-, éste era el escueto argumento esgrimido desde la Dirección general de Instrucción pública, dependiente del Ministerio de Fomento, para eludir la compensación de los 30.000 reales vellón. Comunicado fechado el 3 de mayo de 1858. Archivo de la R. Academia de S. Fernando, legajo 49-7/1. 